\title{
Uma experiência sobre o ensino e aprendizagem de vetores no IFRS com o auxílio do Geogebra
}

\author{
Kelen Berra de Mello* \\ Rodrigo Sychocki da Silva**
}

\begin{abstract}
Resumo: Esse trabalho apresenta o uso do software Geogebra ${ }^{1}$ em uma atividade proposta para o ensino de vetores no plano cartesiano. Trata-se de um conjunto de atividades realizadas com alunos da licenciatura em Matemática na disciplina de Geometria Analítica I. Ao realizar as atividades propostas, os alunos demonstraram o desenvolvimento das habilidades características do pensamento matemático tais como formular hipóteses e argumentar para resolver os problemas. O embasamento teórico para o desenvolvimento da proposta é a teoria dos campos conceituais de Vergnaud, a qual nos ajuda a mostrar que a apropriação dos conceitos matemáticos envolvidos na aprendizagem dos vetores ocorre devido às representações extraídas das situações propostas em sala de aula pelo professor e pela utilização do ambiente virtual pelos alunos.
\end{abstract}

Palavras-chave: Ambientes virtuais; Campos conceituais; Ensino de vetores; Tecnologia.

Abstract: This paper presents the use of software Geogebra in a proposed activity for teaching vectors in the Cartesian plane. This is a set of activities with undergraduate students in mathematics

* Doutora em Engenharia Mecânica pela UFRGS. Professora do IFRS - Caxias do Sul. E-mail: kelen.mello@caxias.ifrs.edu.br

* Doutorando em Informática na Educação pela UFRGS. Professor do IFRS - Caxias do Sul. E-mail: rodrigo.silva@caxias.ifrs.edu.br

1 Software livre, disponível em http://www.geogebra.org/cms/ 
in the discipline of Analytical Geometry I. In carrying out the proposed activities, the students demonstrated the development of the characteristics of mathematical thinking skills such as formulating hypotheses and argue to solve problems. The theoretical basis for the development of the proposal is the theory of Vergnaud's conceptual fields, where we show that ownership of the mathematical concepts involved in learning is due to the vector representations extracted from the situations proposed in the classroom by the teacher and the use of virtual environment by students.

Keywords: Virtual environments; Conceptual fields; Teaching vectors; Technology.

\section{Introdução}

Uma das características da matemática é ser abstrata, e isso exige do aluno que ele desenvolva capacidades cognitivas necessárias para compreender os conceitos que lhe são apresentados durante a graduação. Ao ser egresso do ensino médio e ingressar no curso de licenciatura em matemática, no primeiro ano é de caráter obrigatório a disciplina de Geometria Analítica I, na qual é abordado o conceito de vetor e operações realizadas entre eles.

Ao apresentar o conceito de vetor e iniciar com as operações, percebe-se que apenas as aulas expositivas no quadro não são suficientes para os alunos compreenderem os conceitos, tornando a aprendizagem dificultada. As dificuldades apresentadas pelos alunos são a respeito da visualização e manipulação dos entes geométricos envolvidos. No ensino médio, quando os vetores são abordados, os alunos apresentam inúmeras dificuldades quando as aulas são meramente expositivas utilizando o quadro negro. Essas dificuldades continuam presentes no ensino superior, sendo que os alunos argumentam que não conseguem visualizar as propriedades enunciadas em aula. 
$\mathrm{Na}$ tentativa de amenizar as dificuldades, a estratégia foi utilizar o software Geogebra para auxiliar na aprendizagem dos alunos, procurando uma alternativa para a apresentação desse assunto. A proposta apresentada neste artigo pode ser aplicada em turmas do ensino médio, como uma maneira de possibilitar aos alunos uma aprendizagem qualitativa envolvendo vetores e suas operações. A ideia é relatar uma experiência ocorrida no ensino superior com alunos que recentemente saíram do ensino médio, com o objetivo de apresentar aos professores de ensino básico uma proposta que envolva os seus alunos na apropriação dos conceitos matemáticos, sendo que o uso dos objetos apresentados neste texto motive os professores no desenvolvimento de um trabalho envolvendo tecnologia e ensino de matemática.

$\mathrm{O}$ uso da teoria dos campos conceituais de Vergnaud possibilitou nesse caso desenvolver e aplicar situações em que os alunos, ao manipular os objetos virtuais, atravessariam as três etapas propostas por Vergnaud: através de representaçôes formuladas nos problemas obtém uma referência do conceito, após esse momento ocorre a construção de um significado, e finalmente, para as representações simbólicas adquiridas durante a experiência, é produzido um significante.

Nesse âmbito, as atividades foram desenvolvidas utilizando os recursos disponíveis no software Geogebra e disponibilizadas na Internet, na forma de uma unidade de ensino. As atividades apresentam a possibilidade de manipulação pelo aluno, na forma dinâmica, de cada operação que envolva vetores no plano cartesiano. Uma vez que esse material está disponibilizado na Internet, ele proporciona autonomia e proatividade por parte dos alunos e também que qualquer professor tenha acesso ao material de forma livre.

\section{A teoria dos campos conceituais}

A teoria dos campos conceituais de Gérard Vergnaud é uma teoria que afirma ser a aquisição do conhecimento moldada 
por situações-problemas e pelas ações do sujeito nessas situações. Através das situaçôes-problemas que precisam ser resolvidos é que o aluno percebe o sentido dos conceitos apresentados. $\mathrm{O}$ campo conceitual é colocado como uma unidade de estudo com a finalidade de dar sentido às dificuldades durante o processo de formação do conceito real. Dessa forma, o professor desenvolve o seu trabalho baseado nas dificuldades apresentadas pelos alunos durante a apresentação dos conteúdos em suas aulas.

Bittar (1998), utilizando a teoria dos campos conceituais de Vergnaud, apresenta uma proposta didática utilizando o software Cabri-Géomètre para o ensino de vetores. Em particular, a autora analisou uma turma de alunos do ensino médio de uma escola francesa e estudou as dificuldades deles na aprendizagem do conceito de vetor, a partir da utilização de um ambiente virtual. Através de uma sequência de atividades em ambiente virtual, a autora proporcionou o tratamento de modo dinâmico envolvendo aspectos sobre os vetores que dificilmente são explorados no ambiente papel e lápis. Bittar (1998) fundamentou seus estudos, analisando os livros didáticos mais usados na França, durante os anos de 1994 a 1998.

Com a preocupação que envolve a aprendizagem dos conceitos de matemática, Vergnaud (1982) propõe que o conhecimento está organizado em campos conceituais, cujo domínio por parte dos alunos ocorre ao longo de um período de tempo, através de experiência, maturidade e aprendizagem. Podemos dizer que um campo conceitual é o conjunto de problemas, situações, conceitos, relações, estruturas, conteúdos e operações de pensamento, interligados uns aos outros e provavelmente entrelaçados durante o processo de apropriação na aprendizagem.

Para Vergnaud, as situações não precisam ser necessariamente de caráter didático; podem ser caracterizadas como um conjunto de objetos, propriedades e determinadas relações, envolvendo o sujeito e suas ações. Nesse caso, as situaçốes geram sentido aos conceitos, ou seja, um conceito torna-se significativo 
por meio de uma variedade de situações, e diferentes aspectos de um mesmo conceito estão envolvidos em diferentes situações.

Como as situações geram sentido para os conceitos, os esquemas criados pelos alunos produzem sentido às situações. Em Vergnaud (1990) encontramos que esquema é uma organização invariante da conduta para uma determinada classe de situações. Nesse caso, o comportamento não é considerado invariante, mas sim a organização do comportamento. Isso significa que um esquema é eficiente para qualquer coleção de situações, podendo gerar diferentes sequências de ações, dependendo das características de cada situação em particular.

Podemos dizer ainda que o campo conceitual é definido como um conjunto de situações cujo domínio requer, por sua vez, o domínio de vários conceitos, procedimentos e representações de naturezas distintas. Nesse caso, os conceitos são definidos por três conjuntos: o primeiro é um conjunto de situaçốes que constituem o referente do conceito, o segundo é um conjunto de invariantes operatórios que produzem o significado do conceito e o terceiro é um conjunto de representaçôes simbólicas que constituem o seu significante. A linguagem e os símbolos são ferramentas importantes durante o processo de apropriação dos conceitos pelos alunos e o professor em sala de aula faz uso deles em sua função de mediador; porém devemos considerar que a atitude principal do professor é o de promover situaçôes frutíferas aos alunos, com o objetivo de eles extraírem das situações as representações necessárias para a aprendizagem dos conceitos de matemática.

\section{A proposta}

$\mathrm{Na}$ tentativa de obter uma aprendizagem qualitativa, ao longo do segundo semestre de 2011 foi produzida e aplicada uma sequência de atividades utilizando o software Geogebra. A aplicação das atividades ocorreu com alunos do curso de licenciatura em matemática do Instituto Federal do Rio Grande do Sul (IFRS) - Campus Caxias do Sul, na disciplina de Geometria 
Analítica I. Destacamos que a turma de alunos da disciplina onde as atividades foram aplicadas era constituída por alunos que terminaram o ensino médio há pouco tempo e posteriormente haviam ingressado no curso superior em matemática.

A sequência das atividades propostas está disponibilizada em um domínio público na Internet, onde alunos e outros professores podem em qualquer momento ter acesso. A página inicial conforme mostra a Figura 1, tem a finalidade de apresentar a proposta aos novos visitantes e também serve para orientar os alunos durante a execução da sequência de atividades propostas.

Figura 1: Página inicial das atividades

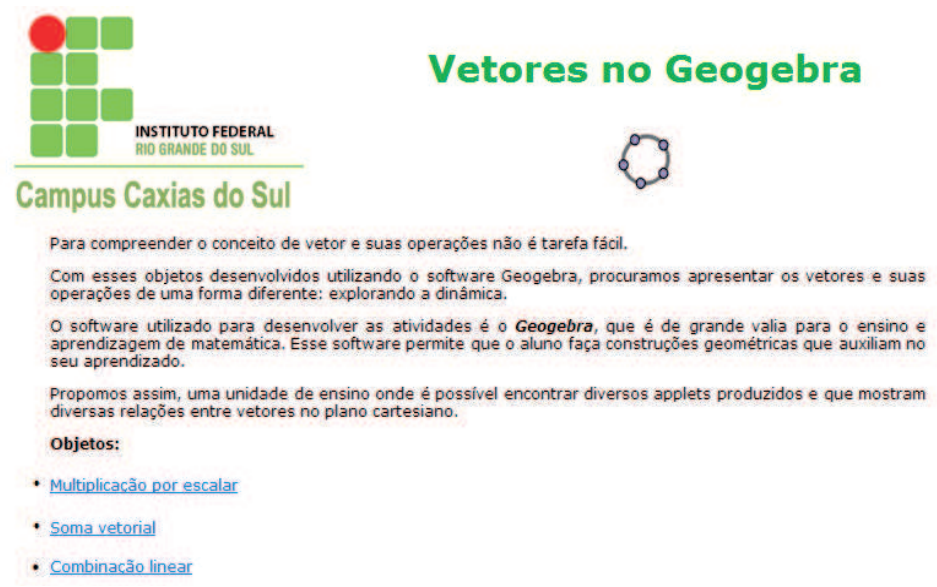

Fonte: http://rodrigomat2004.pbworks.com/w/file/45888819/vetores_geogebra.rar

Os objetos construídos no Geogebra foram transformados em Applets nos quais foram organizados em páginas no formato html e que podem ser acessados através de aplicativos navegadores como, por exemplo, Internet Explorer e Mozilla Firefox. Nesse caso a Internet serve como meio de o aluno buscar o arquivo, que em seguida pode ser usado integralmente no seu computador, dispensando a necessidade da Internet para trabalhar com as atividades. 
Ao acessar o link da multiplicação por escalar, o aluno se depara com uma página conforme mostra a Figura 2, onde ele pode manipular o ponto indicado por $\mathrm{B}$ e fazer com que o vetor $\overrightarrow{A B}$ mude as suas coordenadas. Ao mesmo tempo em que modifica as coordenadas do vetor $\overrightarrow{A B}$, as coordenadas do vetor $\overrightarrow{A C}$ se alteram instantaneamente. Ainda nesse applet, há questionamentos que são importantes para o aluno fazer a reflexão durante o seu momento de aprendizagem. As perguntas foram elaboradas com o objetivo de proporcionar aos alunos a chance de verificar de modo dinâmico as alterações que ocorrem nas coordenadas do vetor azul quando é movimentado o vetor vermelho. Com isso, espera-se despertar a curiosidade matemática do aluno, fazendo-o se dar conta do fato que quando o vetor $\overrightarrow{A B}$ muda

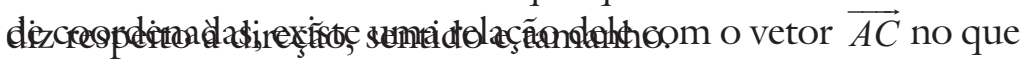

Figura 2: Atividade sobre multiplicação por escalar.

Fonte: http://www.geogebratube.org/student/m26578

\section{[ Multiplicação por escalar ]}

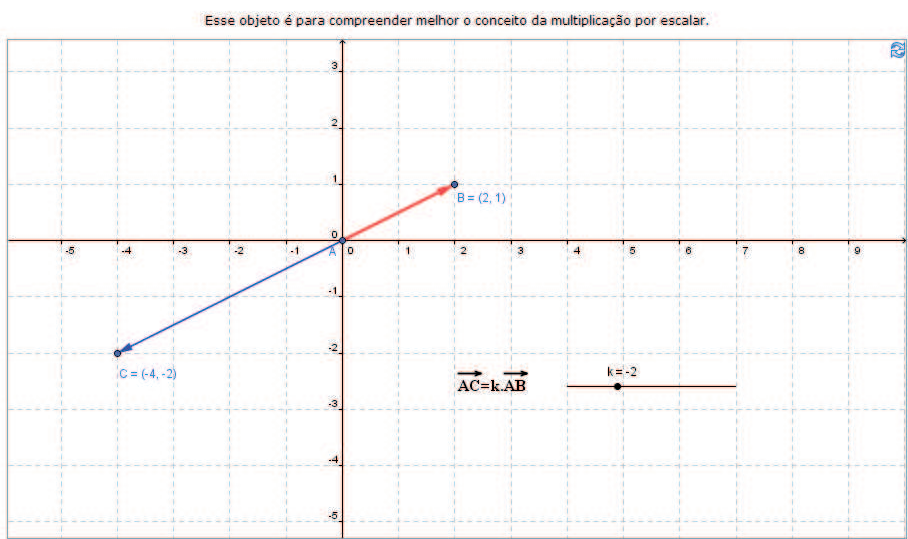

Instruçốes para a atividade:

- Movimente o ponto $B$ e verifique $o$ que acontece com a construção.

- Movimente o ponto $k$ e verifique o que acontece com a construção.

- O que acontece com a direcão e o sentido do vetor AC? Explique.

- Qual a relação que existe entre o tamanho dos vetores AB e AC? Explique.

- Como podemos obter as coordenadas do vetor definido pelos pontos $\mathrm{A}$ e $\mathrm{C}$ em função do vetor $\mathbf{A B}$ ? Explique.

- Esse objeto ajudou você a compreender melhor o conceito de multiplicação por escalar? Explique. 
Ao passar pela experiência de manipular o objeto de multiplicação por escalar, o aluno tem condiçỗes de acessar os demais aplicativos propostos e explorar a soma vetorial e o processo de combinação linear entre vetores. Para acessar as outras atividades, ele retorna até a página principal (Figura l) e acessa pelos outros links as demais páginas.

Segundo Cundy (1997), no momento em que surge a oportunidade de ver e manipular um objeto, o aluno consegue aprender e entender melhor as propriedades matemáticas. Onde há a possibilidade de inserir tecnologia, com o objetivo de auxiliar a aprendizagem, o recurso torna-se ferramenta indispensável pelo professor. Em outras palavras, ao propor o uso desse tipo de objeto, o professor contribui para que o aluno desenvolva autonomia e proatividade em busca do conhecimento proporcionado pelo ambiente virtual.

Em seguida, a soma vetorial é apresentada geometricamente com a regra do paralelogramo e analiticamente como $\overrightarrow{A D}=\overrightarrow{A B}+\overrightarrow{A C}$, conforme Figura 3. Para tornar a soma vetorial mais bem compreendida, propóem-se questionamentos que instigam os alunos para verificar se a figura formada é sempre um paralelogramo, independente da posição dos vetores $\overrightarrow{A C} \mathrm{e}$ $\overrightarrow{A B}$. Com isso, esperou-se que a apresentação dessa situaçãoproblema possibilitasse aos alunos a inserção do campo conceitual necessário para que eles se apropriassem do conceito de soma vetorial. 
Figura 3: Atividade sobre soma vetorial.

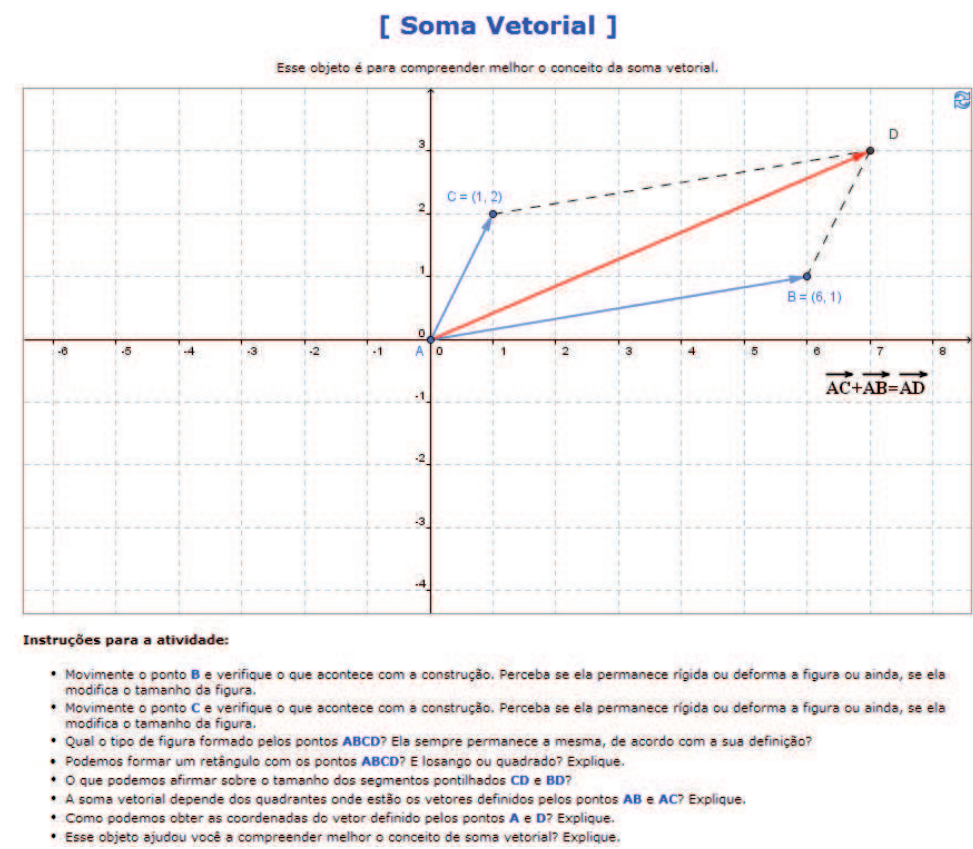

Fonte: http://www.geogebratube.org/student/m26580

A dinâmica no movimento dos pontos B e C são fundamentais, pois conseguimos através dos recursos da geometria dinâmica possibilitar aos alunos a compreensão de algo que antes era considerado fixo e sem interpretação nas aulas de quadro negro e giz. Algumas vezes durante a execução das atividades constatamos que os relatos dos alunos convergiam para o mesmo ponto: durante a escola básica os seus professores não utilizavam alternativas para o ensino de determinados conteúdos, tornando difícil a compreensão dos conceitos de matemática.

Salientamos que o conceito de combinação linear geralmente é visto pelos alunos na graduação como abstrato e sem sentido, impossível de entender pelo chamado método tradicional de aula. O que dificulta a compreensão desse conceito pelos alunos é que, em uma aula considerada tradicional, o quadro 
negro não possibilita que o professor faça movimentos com os vetores, altere os seus parâmetros, e com isso não proporciona uma melhor visualização para os alunos. O fato de desenhar no quadro uma representação da situação na tentativa de melhorar o entendimento de uma propriedade, em termos de precisão e escala, fica comprometido, uma vez que depende do fator qualidade do desenho quando se trata de geometria. Nesse caso, apresentar a combinação linear através do campo conceitual adequado proporciona aos alunos a compreensão do conceito matemático.

Dizemos que uma combinação linear no plano cartesiano é uma equação vetorial da forma $\overrightarrow{A E}=\alpha \overrightarrow{A D}+\beta \overrightarrow{A B}$ onde $\alpha$ e $\beta$ são números reais quaisquer. Vale ressaltar que, a escolha dos parâmetros disponibilizados nos Applets é limitada, uma vez que na tela do computador não é possível visualizar uma combinação linear com quaisquer números reais escolhidos.

Lembramos que na atividade de multiplicação por escalar, os alunos perceberam o que acontecia com o vetor ao multiplicar as suas coordenadas por um parâmetro e isso nesse momento é fundamental para compreender a noção de combinação linear. A proposta dos questionamentos logo abaixo da manipulação é novamente usada aqui, conforme mostra a Figura 4, em que o aluno é conduzido a uma reflexão durante a sua aprendizagem. 
Figura 4: Atividade sobre combinação linear.

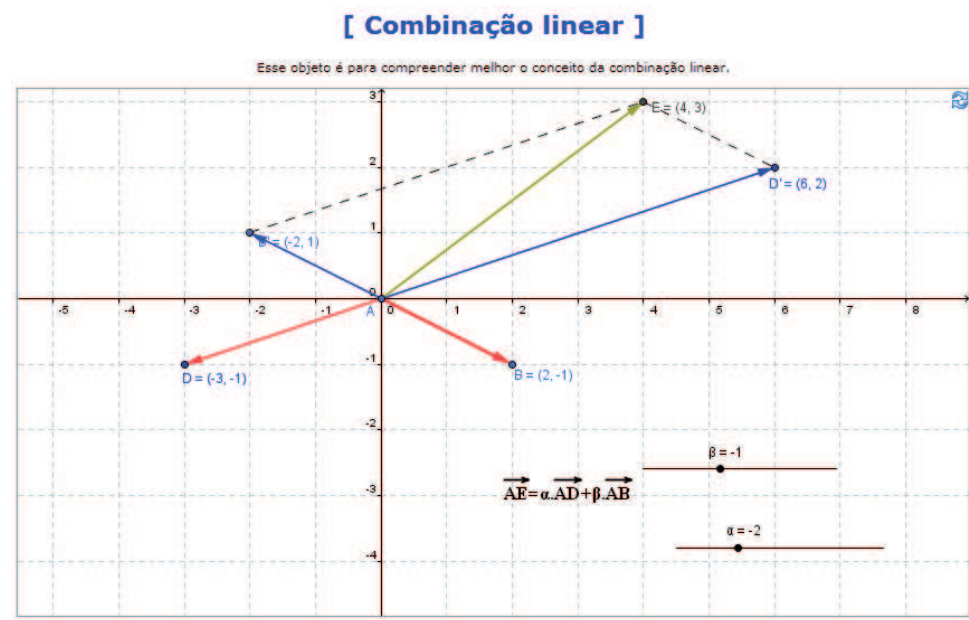

Instruções para a atividade:

- Movimente o ponto $\mathrm{B}$ e verifique 0 que acontece com a construção. Perceba se ela permanece rigida ou deforma a figura ou ainda, se ela modifica o tamanho da figura.

Movimente $O$ Donto D e verifique o que acontece com a construçăo. Perceba se ela permanece rigida ou deforma a figura ou ainda, se ela modifica o tamanho da figura.

- Qual o tipo de figura formado pelos pontos AB'ED'? Ela sempre permanece a mesma, de acordo com a sua definição?

- O que podemos afirmar sobre o tamanho dos segmentos pontilhados $B^{\prime} E \in D^{\prime} E$ ?

- A soma vetorial depende dos quadrantes onde estão os vetores definidos pelos pontos $\mathrm{AB}$ e $\mathrm{AD}$ ? Explique.

- Explore a variaçăo dos parámetros e verifique se é possivel realizar todas as possiveis combinações lineares.

- Represente, genericamente, 0 que é uma combinação linear de dois vetores AB e AD.

- Esse obieto aivida

Fonte: http://www.geogebratube.org/student/m26582

Após a aplicação da proposta foi solicitado aos alunos que os questionamentos já feitos fossem encaminhados para o endereço de e-mail do professor, para que fosse possível realizar uma análise e avaliação da aprendizagem dos alunos. Para Haydt (2002), o conceito de avaliar é atribuir um julgamento ou apreciação de alguma coisa ou de alguém com base em uma escala de valor. Consiste em coletar e interpretar os dados qualitativos e quantitativos de critério preestabelecidos. A principal função da avaliação nesse caso foi verificar as competências, aqui consideradas como conhecimentos, habilidades e atitudes adquiridas pelos alunos durante as atividades, ou seja, se os objetivos da proposta foram atingidos e, também, fornecer aos alunos 
a orientação e o feedback necessários para a construção de seu conhecimento, e não para simplesmente julgar o conhecimento adquirido.

\section{Análise e avaliação da proposta}

As atividades foram aplicadas no laboratório de informática da escola, onde os alunos foram organizados em duplas, sendo que houve a preferência também pela resolução individual das tarefas, conforme a Figura 5. Percebemos que os alunos estavam motivados para a realização das atividades, pois desejavam superar as dificuldades apresentadas durante o ensino básico.

No curso de Geometria Analítica I, através das atividades propostas com o Geogebra, seria o primeiro contato dos alunos com geometria dinâmica. Os alunos envolvidos com a proposta relataram que durante o período da escola básica não haviam participado de uma aula de matemática com o uso de recursos tecnológicos, as suas experiências eram somente com aulas no chamado modo tradicional. Alguns alunos ainda ressaltaram que essa proposta apresentada para o ensino das operaçóes vetoriais possibilitou perceber a matemática de uma outra forma, sendo considerada mais qualitativa do que a maneira utilizada pelo professor durante o seu ensino médio.

Figura 5 - Alunos no momento da execução das atividades.

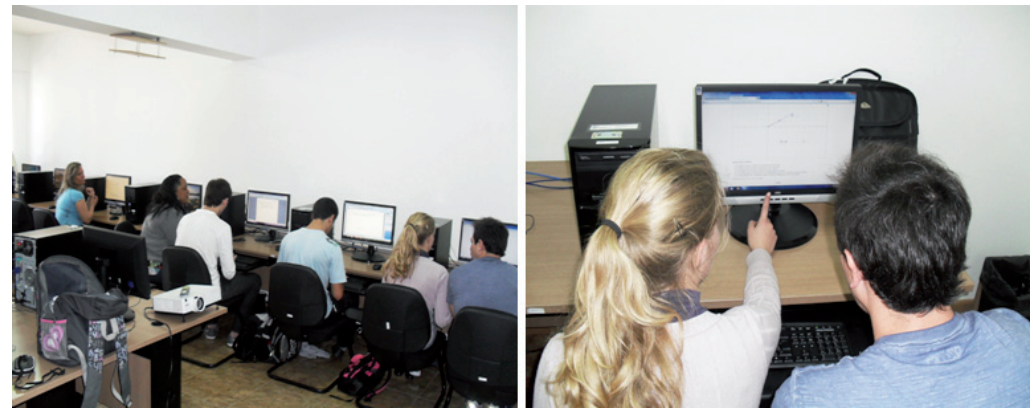

Fonte: Acervo dos autores. 
A seguir é analisada a sequência de atividades desenvolvidas por duas duplas de alunos, com o objetivo de verificar a presença dos campos conceituais durante a realização das atividades.

Atividade sobre multiplicação por escalar

- Movimente o ponto $B$ e verifique o que acontece com a construção.

Dupla 1: Movimentando o B, concluo que o vetor muda de posição, ou seja, muda tamanbo, direção e sentido (comparando com o original). Posso concluir também que a origem é sempre a mesma, ou seja, o A é sempre o $(0,0)$.

Dupla 2: Quando movimentamos o B a resultante $C$ se move proporcionalmente e de forma escalar.

- Movimente o ponto $k$ e verifique o que acontece com a construção.

Dupla 1: Dependendo do número que se escolbe para $k$, temos uma mudança de tamanho (se $k$ for negativo mudará também $o$ sentido) de $A C$ em relação a $A B$.

Dupla 2: Ao movimentarmos $k$ alteramos somente o tamanho da resultante.

- $\mathrm{O}$ que acontece com a direção e o sentido do vetor $A C$ ? Explique.

Dupla 1: $A$ direção de $A C$ é sempre a mesma de $A B$. Já o sentido pode mudar se o $k$ for negativo, ou ficar igual se $k$ for positivo. Dupla 2: Muda de acordo com a direção de B e o sentido de $k$.

- Qual a relação que existe entre o tamanho dos vetores $A B$ e $A C$ ? Explique.

Dupla 1: Se k for 1 ou -1, o vetor $A B$ é de mesmo tamanho de $A C$; se k for maior que 1 e menor que -1, $A C$ será maior que $A B$; se k for de 1 a 0 e 0 a-1, $A C$ será menor que $A B$; se $k$ for zero $A B=A C$; se $k$ for de 0 .

Dupla 2: $A$ relação é que quando $k=1, A B=A C$. 
- Como podemos obter as coordenadas do vetor definido pelos pontos $A$ e $C$ em função do vetor $A B$ ? Explique.

Dupla 1: É a fórmula, $A C=k A B$. Mudando $k$ muda $A C$ em relação $A B$.

Dupla 2: As coordenadas de $A C$ são iguais a k vezes $A B$.

- Esse objeto ajudou você a compreender melhor o conceito de multiplicação por escalar? Explique.

Dupla 1: Com certeza, a visualização é muito melhor que no quadro.

Dupla 2: Sim, pois podemos ver as relaçôes em todos os quadrantes e percebendo a mudança de tamanho em função da variável $k$.

$\mathrm{Na}$ apresentação desse objeto envolvendo geometria dinâmica, percebe-se que o campo conceitual sobre a multiplicação por escalar apresentado aos alunos foi suficiente para que eles extraíssem a representação usada na interpretação de mudança no sentido e tamanho do vetor envolvido. A interação proposta pela animação possibilitou a verificação na existência da proporcionalidade envolvendo as coordenadas dos vetores envolvidos, possibilitando assim a formação do significado dessa operação entre vetores. Ao realizar essa primeira atividade, percebe-se uma convergência nas respostas dadas pelas duplas anteriormente. A importância da dinâmica no objeto é fundamental, uma vez que é possível estabelecer relações instantâneas, conjecturar hipóteses, verificar a sua validade ou obter um contraexemplo. Enfim, iniciase assim o processo de pensamento matemático.

\section{Atividade sobre Soma Vetorial}

- Movimente o ponto $B$ e verifique o que acontece com a construção. Perceba se ela permanece rígida ou deforma a figura ou ainda, se ela modifica o tamanho da figura. 
Dupla 1: A figura é sempre rígida, sendo que mexendo $B$ mudamos o tamanho da figura.

Dupla 2: Mantém o paralelogramo, é rígida e modifica o tamanho da figura.

- Movimente o ponto $C$ e verifique o que acontece com a construção. Perceba se ela permanece rígida ou deforma a figura ou ainda, se ela modifica o tamanho da figura.

Dupla 1: A figura é sempre rígida, sendo que mexendo $A$ mudamos o tamanho da figura.

Dupla 2: Mantêm o paralelogramo, é rigida e modifica o tamanho da figura.

- Qual o tipo de figura formado pelos pontos $A B C D$ ? Ela sempre permanece a mesma, de acordo com a sua definição?

Dupla 1: Paralelogramo, e sempre é a mesma.

Dupla 2: Paralelogramo, sim permanece a mesma com lados paralelos.

- Podemos formar um retângulo com os pontos $A B C D$ ?

E losango ou quadrado? Explique.

Dupla I: Sim, pois de um paralelogramo podemos obter um losango, quadrado.

Dupla 2: Sim, pois eles tem as propriedades do paralelogramo.

- O que podemos afirmar sobre o tamanho dos segmentos pontilhados $C D$ e $B D$ ?

Dupla 1: Temos $C D=A B$ e $B D=A C$.

Dupla 2: São proporcionais ao segmento $A B$ e $A C$.

- A soma vetorial depende dos quadrantes onde estão os vetores definidos pelos pontos $A B$ e $A C$ ? Explique.

Dupla 1: Não depende, pois sempre podemos obter uma soma vetorial. 
Dupla 2: Não depende, o pensamento é igual em todos os quadrantes.

- Como podemos obter as coordenadas do vetor definido pelos pontos $A$ e $D$ ? Explique.

Dupla 1: Fazendo a conta $A C+A B=A D$.

Dupla 2: Pela soma dos vetores $A B+A C$.

- Esse objeto ajudou você a compreender melhor o conceito de soma vetorial? Explique.

Dupla 1: Com certeza, pois assim podemos fazer somas mais rapidamente.

Dupla 2: Sim, pois a visualização foi clara com diversos tipos de tamanhos e formas.

Nas atividades sobre a soma vetorial os alunos demonstram conhecimentos prévios de geometria plana, onde fundamentaram as suas respostas sempre apelando para as propriedades geométricas das figuras. Percebe-se neste momento, o domínio do raciocínio generalista da matemática, onde os alunos afirmam que a soma vetorial independe do quadrante onde os vetores estão representados. Neste caso, o campo conceitual proposto aos alunos envolvia conhecimentos de geometria plana que deveriam ser lembrados e usados na soma de vetores. Percebe-se que as referências utilizadas pelos alunos para a formação do significado durante as atividades foram extraídas em grande parte de resultados de geometria plana onde o significante já havia sido apropriado.

Atividade sobre Combinação Linear

- Movimente o ponto $B$ e verifique o que acontece com a construção. Perceba se ela permanece rígida ou deforma a figura ou ainda, se ela modifica o tamanho da figura. 
Dupla 1: Sempre é rígido, continua sempre paralelogramo, e modifica sim o tamanho.

Dupla 2: Ela é rígida e há modificação no tamanho.

- Movimente o ponto D e verifique o que acontece com a construção. Perceba se ela permanece rígida ou deforma a figura ou ainda, se ela modifica o tamanho da figura.

Dupla 1: Sempre é rígido, continua sempre paralelogramo e modifica sim o tamanho.

Dupla 2: Ela é rígida e há modificação no tamanho.

- Qual o tipo de figura formado pelos pontos $A B^{\prime} E D^{\prime}$ ? Ela sempre permanece a mesma, de acordo com a sua definição?

Dupla 1: Paralelogramo, sempre é a mesma.

Dupla 2: Paralelogramo. Sim permanece a mesma.

- O que podemos afirmar sobre o tamanho dos segmentos pontilhados $B^{\prime} E$ e $D^{\prime} E$ ?

Dupla 1: Temos $B E=A D$ e $D E=A B$.

Dupla 2: São paralelos e iguais a $A B^{\prime}$ e $A D$ '.

- A soma vetorial depende dos quadrantes onde estão os vetores definidos pelos pontos $A B$ e $A D$ ? Explique.

Dupla 1: Não, sempre podemos obter a soma vetorial, independente do quadrante.

Dupla 2: Não depende dos quadrantes.

- Explore a variação dos parâmetros e verifique se é possível realizar todas as possíveis combinações lineares.

Dupla 1: Todas não, irracional não dá.

Dupla 2: Não por que os números irracionais são impossiveis de serem representados no computador.

- Represente, genericamente, o que é uma combinação linear de dois vetores $A B$ e $A D$. 
Dupla 1: Parámetro do vetor $A B$ mais parámetro do vetor $A D$ é igual a vetor $A E$.

Dupla 2: Fazemos x.AB+y.CD e obtemos o vetor maior.

- Esse objeto ajudou você a compreender melhor o conceito de combinação linear? Explique.

Dupla 1: Com certeza, pois é mais fácil de visualizar.

Dupla 2: Sim, pois visualizamos geometricamente as propriedades do paralelogramo.

Com a aquisição do conceito da multiplicação por escalar e da soma vetorial, os alunos foram conduzidos para o conceito de combinação linear, de modo que a organização das referências previamente extraídas fez com que eles compreendessem o que é uma combinação linear entre vetores. Destacamos ainda nessa última atividade, além da convergência das respostas, um dos questionamentos propostos fez com que os alunos refletissem sobre a representação dos números nos computadores. Ao afirmar que os números irracionais não podem ser representados exatamente no computador, os alunos demonstraram o domínio do conhecimento matemático sobre a construção e representação dos números reais no computador. Em suma, pode-se dizer que a proposta do uso desses objetos construídos no Geogebra contribuiu significativamente para a compreensão dos conceitos envolvidos com vetores e suas operações.

\section{Considerações finais}

O software Geogebra possui inúmeras aplicações na sala de aula. Ele não é um software de difícil acesso, pois a sua licença é gratuita. Cabe ao professor conhecer e divulgar as possibilidades de seu uso. A possibilidade que é apresentada neste artigo, refere-se ao seu uso para o ensino de vetores, mas há trabalhos que apresentam o seu uso para o ensino de funções lineares, quadráticas, entre outras aplicações relacionadas com geometria. 
Destacamos que essas atividades constituem uma experiência realizada com alunos no início da graduação, mas certamente podem ser aplicadas com alunos no ensino médio nas aulas de matemática ou física. Além de enriquecer o momento da aula, é um modo de proporcionar aos alunos condiçôes para uma aprendizagem qualitativa. Abordar as operações vetoriais com objetos envolvendo geometria dinâmica é uma alternativa para levar até aos alunos uma maneira de compreender melhor os conteúdos desenvolvidos. Neste caso, a teoria dos campos conceituais de Vergnaud foi essencial para apresentar que a aprendizagem ocorreu quando foi proposto uma alternativa para os alunos visualizar dinamicamente as propriedades que estão intrínsecas aos vetores, ou seja, eles devem passar pela experiência de manipulação dos objetos. Depois de vivenciar essa experiência, é produzido um significado e ao final um significante, em que os alunos organizam a sua aprendizagem através representações simbólicas extraídas das situações-problema propostas.

\section{Referências}

BITTAR, Mariulena. Les vecteurs dans l'enseignement secondaire. Aspects outil et objet dans les manuels. Etude de difficultés d'élèves dans deux environnements: papier crayon et Cabri-géomètre II. Tese de Doutorado da Universidade Joseph Fourier, Grenoble 1, 1998.

CUNDY, Henry Martyn; ROLLETT, Arthur Percy. Mathematical Models. London: Tarquin, 1997.

HAYDT, Regina C. Avaliação do processo ensino-aprendizagem. São Paulo: Ática, 2002.

VERGNAUD, Gerard. A classification of cognitive tasks and operations of thought involved in addition and subtraction problems. In: CARPENTER, T.; MOSER, J.; ROMBERG, T. Addition and subtraction. A cognitive perspective. Hillsdale, N. J.: Lawrence Erbaum. 1982. p. 39-59. 
VERGNAUD, Gerard. A comprehensive theory of representation for mathematics education. Journal of Mathematical Behavior. 1998. p. 167181.

VERGNAUD, Gerard. A teoria dos campos conceptuais. In: BRUM, João. (Org.). Didáctica das Matemáticas. Lisboa: Horizontes pedagógicos, 1996. p. 155-191.

VERGNAUD, Gerard. La théorie des champs conceptuals. Récherches em Didactique dês Mathématiques. 1990. p. 133-170.

VERGNAUD, Gerard. Multiplicative conceptual Field: what and why? In: GUERSHON, H.; CONFREY, J. The development of multiplicative reasoning in the learning of mathematics. Albany, N. Y.: State University of New York Press. 1994. p. 41-59. 